\title{
Revealing the diversity of a once small taxon: the genus Selenoribates (Acari, Oribatida, Selenoribatidae)
}

\author{
Tobias Pfingst $1^{1,2, \dagger}$ \\ I Bermuda Institute of Ocean Sciences Inc. (BIOS), 17 Biological Lane, St. George's GE 01, Bermuda 2 Institute \\ of Zoology, University Graz, Universitaetsplatz 2, 8010 Graz, Austria \\ † urn:lsid:zoobank.org:author:9COB36D7-86B5-46A6-A99E-00BECD5CD9BC \\ Corresponding author: Tobias Pfingstl (dr.tobias.pfingstl@uni-graz.at)
}

Academic editor: Vladimir Pesic | Received 6 May 2013 | Accepted 20 June 2013 | Published 24 June 2013

urn:lsid:zoobank.org:pub:2AB22C8B-72C0-41B2-BACA-70F5E8814DFD

Citation: Pfingstl T (2013) Revealing the diversity of a once small taxon: the genus Selenoribates (Acari, Oribatida, Selenoribatidae). ZooKeys 312: 39-63. doi: 10.3897/zookeys.312.5478

\begin{abstract}
Three new intertidal oribatid species, Selenoribates elegans sp. n., Selenoribates quasimodo sp. n. and Selenoribates satanicus sp. $\mathbf{n}$. are described from the archipelago of Bermuda. Selenoribates elegans sp. $\mathbf{n}$. is characterized by its slender body shape, $S$. quasimodo sp. n. possesses a hunchback in lateral view and $S$. satanicus sp. n. exhibits two horn-like projections on its anterior gastronotic region. Based on these new findings, the number of Selenoribates species doubled at once and the distribution of this genus, formerly limited to the Mediterranean and the Red Sea, includes now occurrences in the Atlantic and Indo-pacific Ocean as well. The morphology of $S$. quasimodo sp. n. and $S$. satanicus sp. n. deviates conspicuously from the other known members of Selenoribates, thus indicating that not only the number of species but also the anatomy of this genus is more diverse than formerly supposed. Nymphs of S. quasimodo sp. n. show an interesting case of ontogenetic neotrichy, with gastronotic setae being duplicated with each moult.
\end{abstract}

\section{Keywords}

Bermuda, intertidal, juvenile instars, Selenoribates, biogeography 


\section{Introduction}

The family of Selenoribatidae represents a group of littoral oribatid mites. These mites are air-breathing terrestrial organisms, but they have managed to colonize marine associated habitats and are now exclusively confined to intertidal zones of coastal areas (Pfingstl 2013). They show a transoceanic distribution and occur on shores of the tropics and subtropics (e.g. Schuster 1989, Procheş and Marshall 2001). At present, this family consists of seven genera, namely Arotrobates Luxton, 1992, Carinozetes Pfingstl and Schuster, 2012, Psednobates Luxton, 1992, Rhizophobates Karasawa \& Aoki, 2005, Schusteria Grandjean, 1968, Selenoribates Strenzke, 1961 and Thalassozetes Schuster, 1963. Rhizophobates and Schusteria have been subject to taxonomic debates (e.g. Karasawa and Aoki 2005, Pfingstl and Schuster 2012) and the discreteness of some members of these genera is still unclear. The other genera are yet well delimited and the same applies to the genus type Selenoribates. Strenzke (1961) described the first species of this taxon, Selenoribates foveiventris, then Grandjean (1966) discovered S. mediterraneus, and finally Abd-El-Hamid (1973) added the third species, S. ghardaqensis. Since that time no further species have been detected and not even a single record of the already known species has been published. Accordingly the genus Selenoribates, with only three species, was supposed to be a small taxon with a restricted distribution in the Mediterranean and the Red Sea. The descriptions of the known species provided ample data on the morphology of the adults (Strenzke 1961, Grandjean 1966, Abd-El-Hamid 1973) but only one author (Grandjean 1966) described the nymphs of $S$. mediterraneus. Concerning the ecology and biology, virtually nothing is known about these species.

In the course of a recent study on intertidal oribatid mites from Bermuda, three new Selenoribates species could be discovered and this finding changes biogeographic and morphological aspects of this genus dramatically. Therefore this paper describes the morphology of the three new species, modifies the distribution pattern and tries to answer the question why the genus Selenoribates has vanished into thin air for more than forty years.

\section{Material and methods}

Intertidal algae growing on sandy and rocky substrate, as well as on roots of the black mangrove (Avicennia germinans) were collected on the archipelago of Bermuda during low tide and afterwards put in a Berlese-Tullgren apparatus for the extraction of mites. For investigation in transmitted light all animals were stored in ethanol $(70 \%$ or pure ethanol), then heated in lactic acid $\left(80^{\circ} \mathrm{C}\right.$ for about 20 minutes) and afterwards embedded in BERLESE mountant. Observations, photographs and drawings were made with an Olympus BH-2 Microscope equipped with a drawing attachment. Image stacks were obtained by an Olympus E1 digital camera and layered with the Combine ZP software. Inscriptions of drawings were done according to Grandjean $(1966,1968)$. 


\section{Results}

\section{Family Selenoribatidae Schuster, 1963}

\section{Genus Selenoribates Strenzke, 1961}

http://species-id.net/wiki/Selenoribates

Remarks. The following diagnosis summarizes the characters provided by Strenzke (1961), Grandjean (1966), Abd-El-Hamid (1973) and includes the characters of the present descriptions.

Small sized $(198-308 \times 119-185 \mu \mathrm{m})$ intertidal mites. Cerotegument granular. Interlamellar setae short or minute. Lamellar ridges present but short. Sensillus flagelliform and long. Pedotectum I small but robust, pedotectum II absent. Notogaster with 14 pairs of setae, $c_{3}$ absent. Obvious depressions, variable in number and shape, present on anterior part of notogaster. Two median epimeral cavities present. Epimeral setal formula 1-0-1-1. Genital plates with three-four pairs of setae. Aggenital setae absent. Twothree pairs of adanal setae and one-three pairs of anal setae. Legs monodactylous; claws with one or two proximoventral teeth. Juveniles plicate with large centrodorsal plate.

\section{Selenoribates quasimodo sp. $\mathbf{n}$.}

urn:Isid:zoobank.org:act:CA3698B8-B235-4EAA-8DC3-E3F1DDDF7D84 http://species-id.net/wiki/Selenoribates_quasimodo

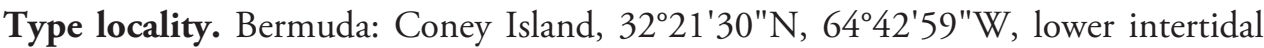
area, sand and algae growing on mangrove roots, 18 October 2011.

Type specimen. Holotype: male, preserved in pure ethanol, deposition: Naturhistorisches Museum Wien, collection nr. NHMW 21884. Paratypes: two males, deposition: Senckenberg Museum für Naturkunde Görlitz, collection Nr. 11/48677.

Diagnosis. Red-brown sclerotized mites. Average length $228 \mu \mathrm{m}$, mean width $139 \mu \mathrm{m}$. Notogaster rounded in dorsal view, hunchbacked in lateral view. A large anteriorly arched depression on anterior part of notogaster. Lamellar ridges short. Interlamellar seta of normal length and spiniform. Fourteen pairs of spiniform notogastral setae. Uniform median epimeral cavity. Three pairs of genital, two pairs of adanal and two pairs of anal setae present. Legs monodactylous; claw of each leg large. Claw with one proximoventral and a proximodorsal tooth. No porose areas on femora discernable.

Description. Adult: Females ( $=14)$, length: $222-244 \mu \mathrm{m}$ (mean $231 \mu \mathrm{m}$ ), width: 136-152 $\mu \mathrm{m}$ (mean $142 \mu \mathrm{m})$; males $(\mathrm{N}=16)$, length: $212-238 \mu \mathrm{m}$ (mean 226 $\mu \mathrm{m})$, width: 131-147 $\mu \mathrm{m}$ (mean $137 \mu \mathrm{m})$

Integument. Colour red brown. Cerotegument appears basically slightly granular. Cerotegument of prodorsum nearly smooth between bothridia, strongly granular anterior and lateral to lamellar ridges. Cerotegument of notogaster and venter slightly 


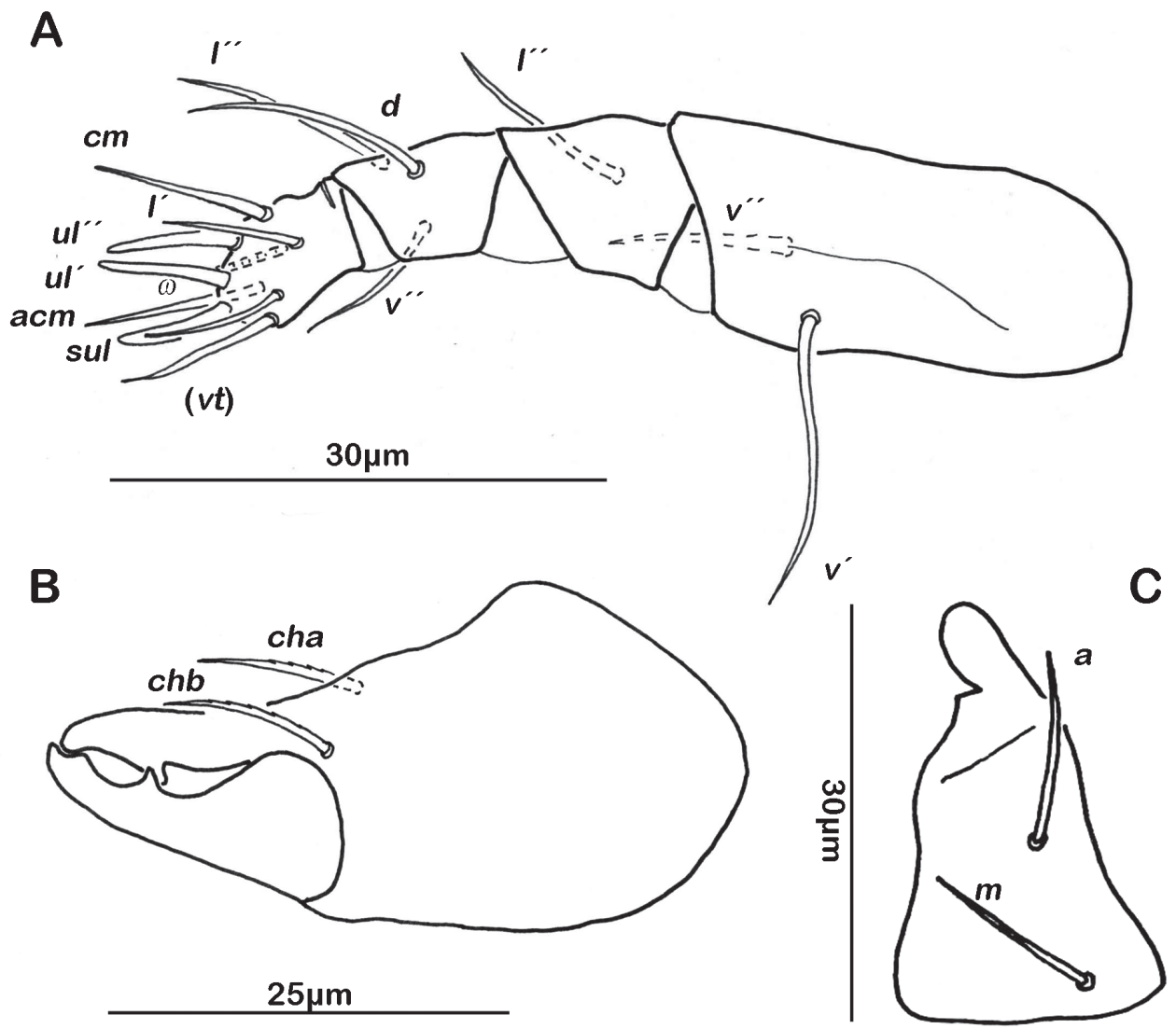

Figure I. Selenoribates quasimodo sp. n. mouthparts. A left pedipalp antiaxial view B left chelicera antiaxial view $\mathbf{C}$ right rutellum ventral view.

granular. Cerotegument of lateral body parts generally finely granular, larger granules in areas surrounding acetabula. Cerotegument of legs slightly granular.

Prodorsum. Rostrum rounded in dorsal view, but slightly projecting anteroventrally in lateral view. Rostral setae ( $r o$ ) short and smooth. Lamellar setae (le) and interlamellar setae (in) simple, short and smooth. Exobothridial setae (ex) minute. Lamellar ridge conspicuous, but short, not reaching insertions of lamellar setae. Bothridium large cup exhibiting a strongly projecting posterior ridge with three lobe-like protrusions overhanging anterior border of gastronotic region. Sensillus long (ca. $50 \mu \mathrm{m})$ and flagelliform. Tutorium developed as slightly dorsally curved ridge.

Gnathosoma. Pedipalp pentamerous 0-2-1-3-9 (including solenidion) (Fig. 1A). Solenidion erect, not fused with eupathidium acm. Chelicera chelate, in lateral view forceps-like and each digit with two teeth, whereas from frontal view most distal teeth split into two symmetrical teeth (Fig. 1B). No porose area on proximal part of fixed digit discernable. Seta $c h a$ and $c h b$ dorsally slightly pectinate, both same length. Distal part of rutellum developed as thin triangular slightly curved inward mem- 
A

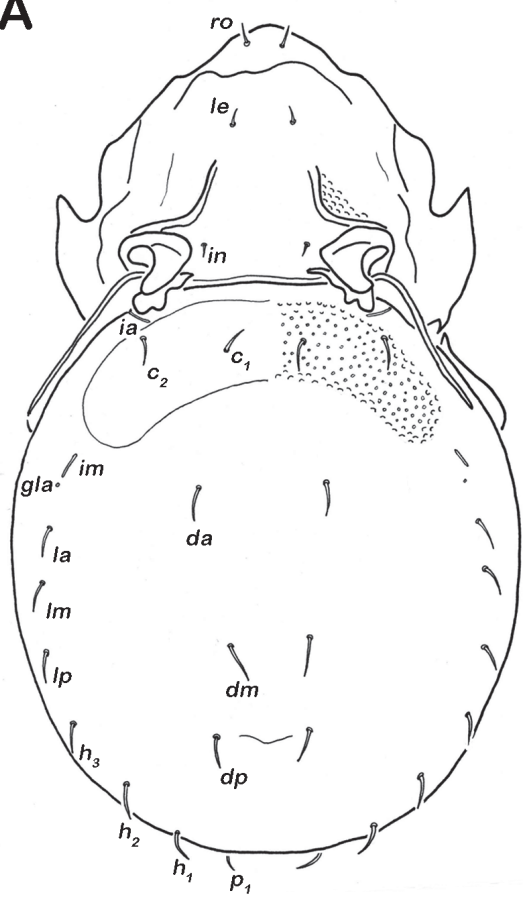

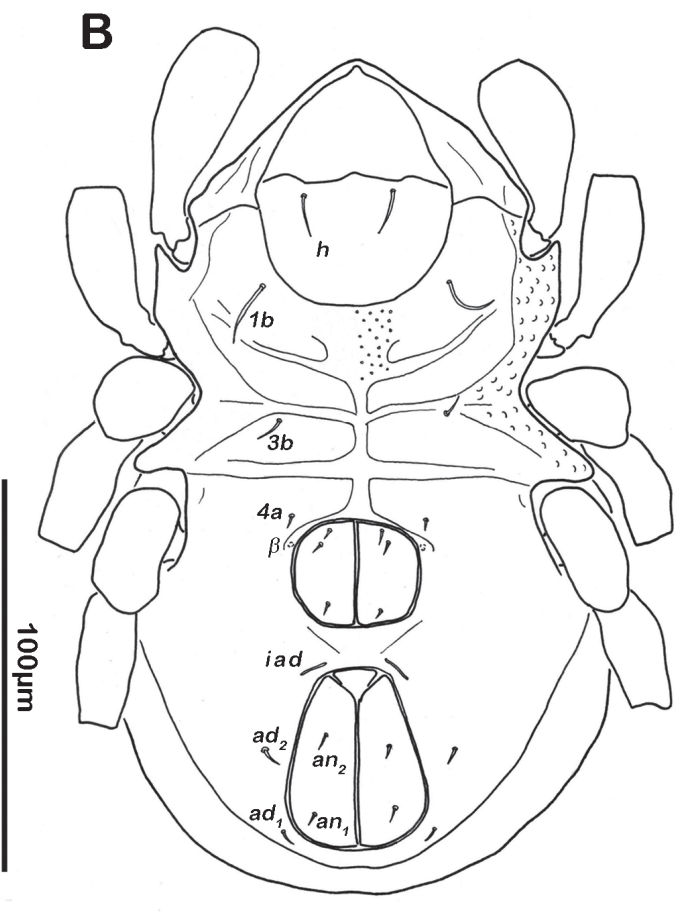

C

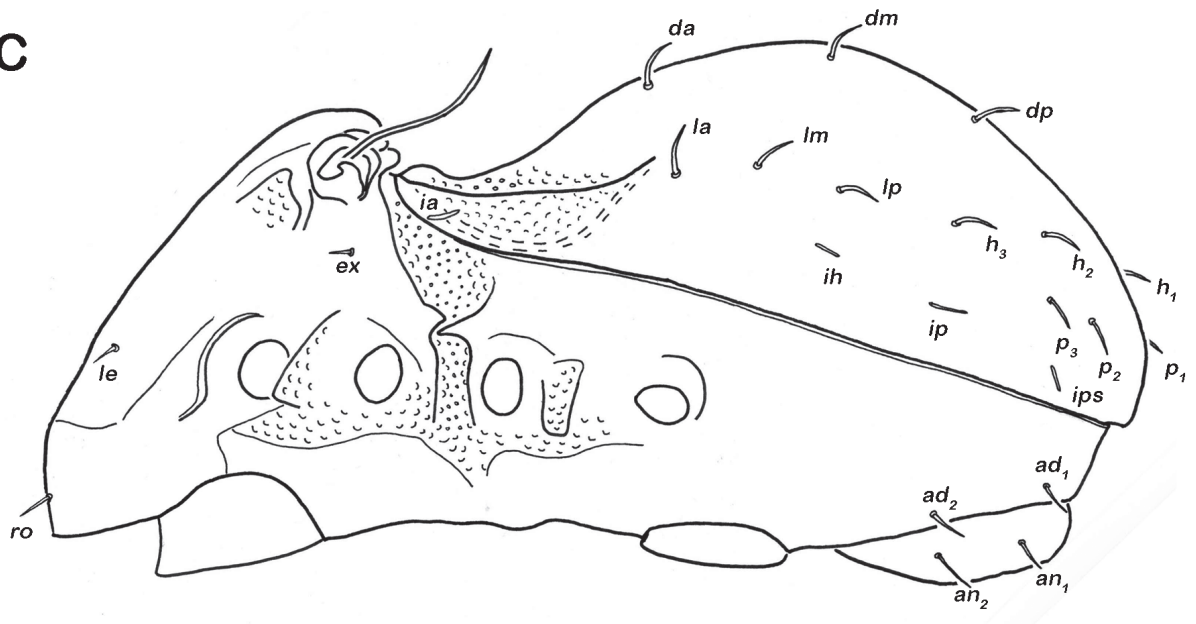

$100 \mu \mathrm{m}$

Figure 2. S. quasimodo sp. n. adult. A dorsal view B ventral view $\mathbf{C}$ lateral view.

brane (Fig. 1C). Setae $a$ and $m$ long and smooth. Mentum regular, setae $h$ simple, thin and long.

Notogaster (Figs 2A, 3A). Rounded in dorsal view, hunchbacked in lateral view. Anterior margin of notogaster distinct. A large, arched depression on anterior part of notogaster showing obvious granulation. Fourteen pairs of simple notogastral 

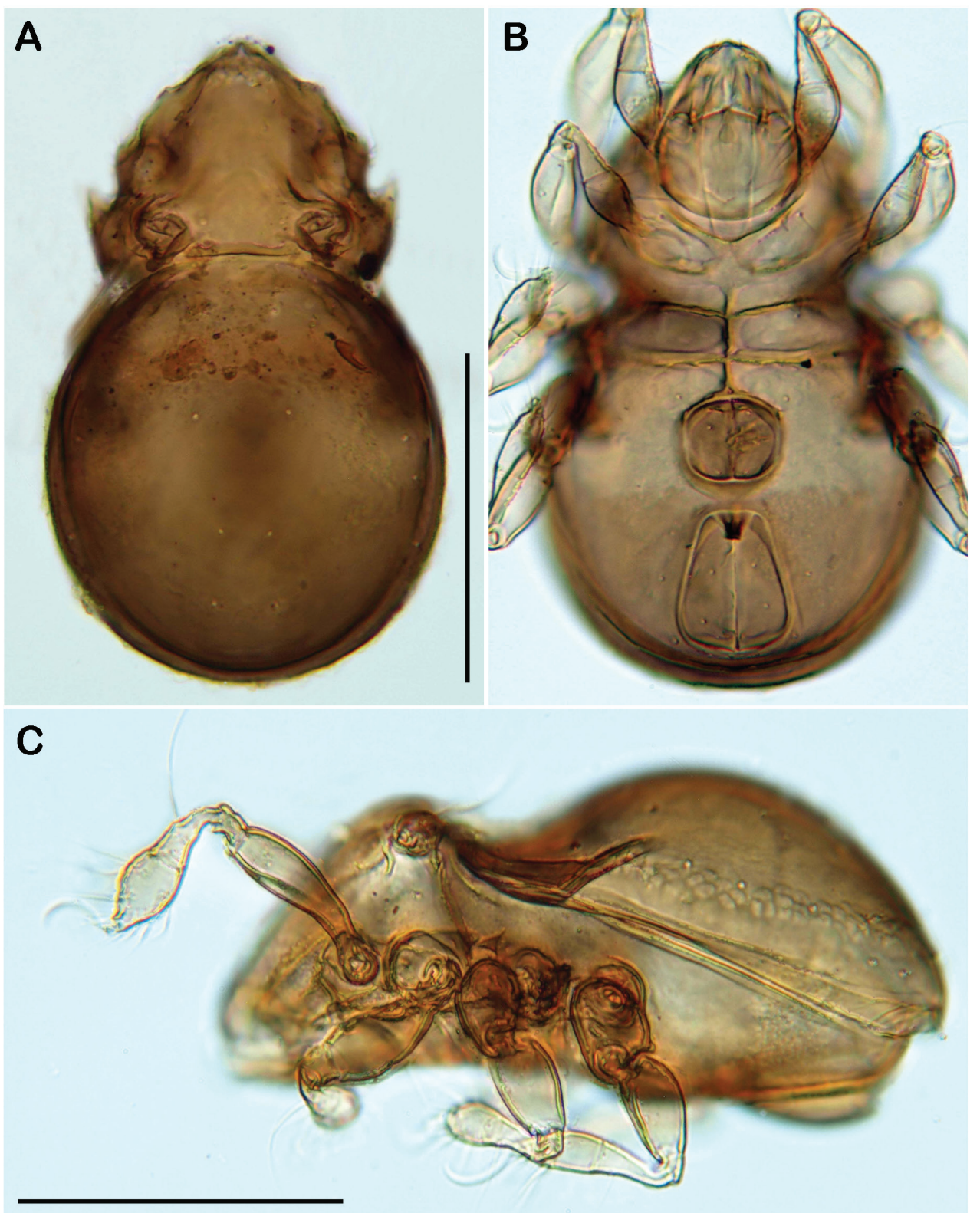

Figure 3. S. quasimodo sp. n. adult micrographs layered from 5-10 sequentially focused images. A dorsal view $\mathbf{B}$ ventral view $\mathbf{C}$ lateral view. Scale bars $=100 \mu \mathrm{m}$.

setae (approximate length 5-7 $\mu \mathrm{m}), c_{1-2}, d a, d m, d p, l a, l m, l p, h_{1-3}, p_{1-3} ; c_{3}$ absent. Notogastral setae sometimes completely covered by a layer of cerotegument. Porose areas or distinct pores absent. Five pairs of notogastral lyrifissures present; ia next to setae $c_{2}$ close and rectangular to anterior notogastral border; im slightly anterior and laterad of setae $l a$; lyrifissures $i h$, ip and ips laterally close to lateroventral bor- 
ders of notogastral plate. Opisthonotal gland openings (gla) located posteriorly to lyrifissures im.

Lateral aspect (Figs 2C, 3C). Pedotectum I small but thick, pedotectum II absent. Lateral parts of anterior margin of notogaster broad and deep, showing conspicuous granules. Enantiophyse consisting of two strong triangular teeth orientated against each other. Discidium developed as strong rectangular bulge between acetabulum III and IV.

Ventral region of idiosoma (Figs 2B, 3B). Epimeral setation 1-0-1-1, seta $1 b$ long reaching trochanter II, setae $3 b$ normal length and $4 a$ short. Internal borders of all epimera well visible, sternal apodemes II, sejugal and III well developed. A densely granulated median sternal cavity on epimeron I. Three pairs of short and fine genital setae, arranged in longitudinal rows, anterior two pairs close to each other. Insertion of tendon $\beta$ next to anterior corners of genital orifice. Aggenital setae absent. Anal plates triangular. Preanal organ triangular in ventral view. Two pairs of short anal setae, $a n_{1-2,}$ present. Two pairs of short and simple adanal setae $a d_{1-2}$ present, $a d_{3}$ absent. Lyrifissure iad obliquely, adjacent to anterior corners of anal orifice.

Legs. Monodactylous. Long hook-like claws with one conspicuous proximoventral and one minuscule proximodorsal tooth. Trochanters III and IV with an obvious triangular dorsodistal projection. Femora with slightly projecting ventral carinae. All tarsi with one proximal lyrifissure. No porose areas on femora discernable. Solenidia $\varphi_{1}$ on tibia I long and orientated backwards. Chaetome and Solenidia see Table 1.

Etymology. The specific name refers to Quasimodo, the famous bell-ringer of Victor Hugo's historical novel "Notre-Dame de Paris" (1831). This appellation is due to the hunchback of this species shown in lateral view (that does not necessarily mean the species is as ugly as the bell-ringer was supposed to be). The name is given as noun in apposition.

Juvenile instars - common features. Apheredermous. Colour light brown. Integument strongly plicate, except for centrodorsal plate. Thick layer of cerotegument covering whole body. Prodorsum triangular, rostrum rounded. Rostral and lamellar setae short and smooth. Exobothridial setae reduced to a circular vestigial structure. Interlamellar setae very short. Sensillus long and flagelliform. Bothridium large cup, laterally opened. Gnathosoma no obvious differences to adult instar. Hysterosoma slightly concave, plateau-like. Slightly plicate centrodorsal plate occupying two thirds of dorsal hysterosoma, bearing centrodorsal setae. Hysterosomal cupules not discernable in any instar. Large folds framing centrodorsal plate completely, showing fine granular surface. Orifice of opisthonotal gland laterad of seta $a d_{2}$. Integument surrounding anogenital area folded. Dorsal setae of tibiae and genua absent. No porose areas detectable in any stage.

Protonymph. Length (N=3): 172-209 $\mu$ m (mean $191 \mu \mathrm{m})$

Gastronotic region (Fig. 4A) with 24 pairs of notogastral setae; setae $c_{1-3}, d a, d m$, $d p$, la, Im and $l p$ duplicated, $h_{1-3}$ and $p_{1-3}$ normal. Centrodorsal setae $d a, d m$ and $d p$ robust and dorsally serrate, all other setae simple and small.

Ventral region of idiosoma (Fig. 4B). Epimeral setation 1-0-1-0. One pair of short genital setae. 


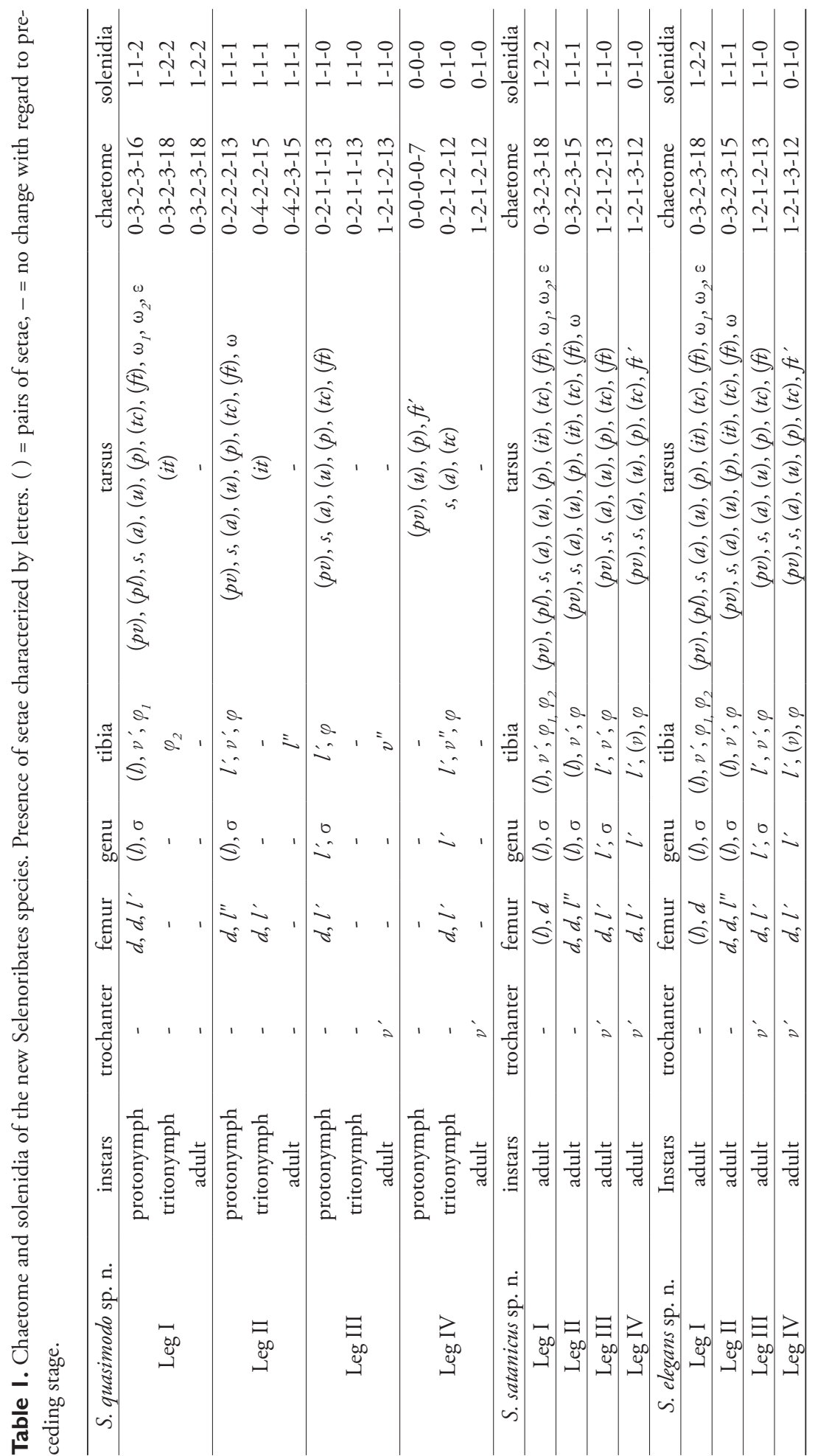


A

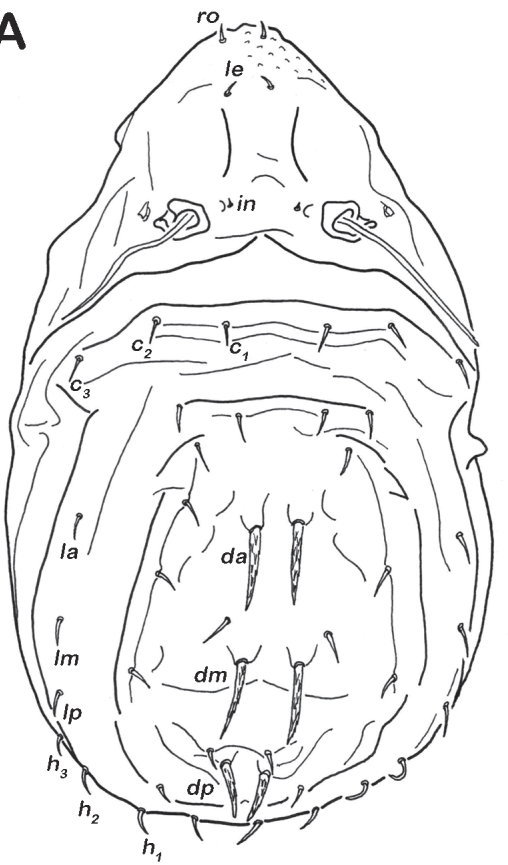

C

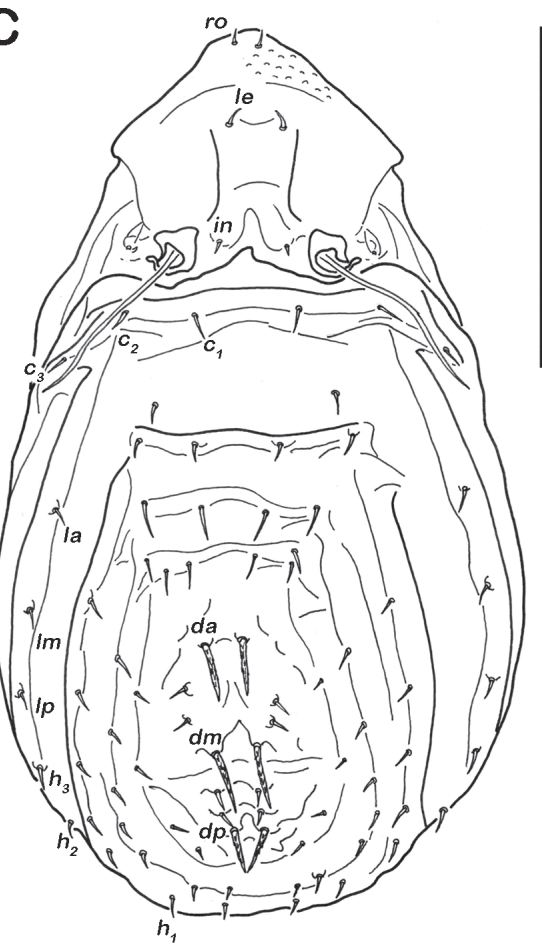

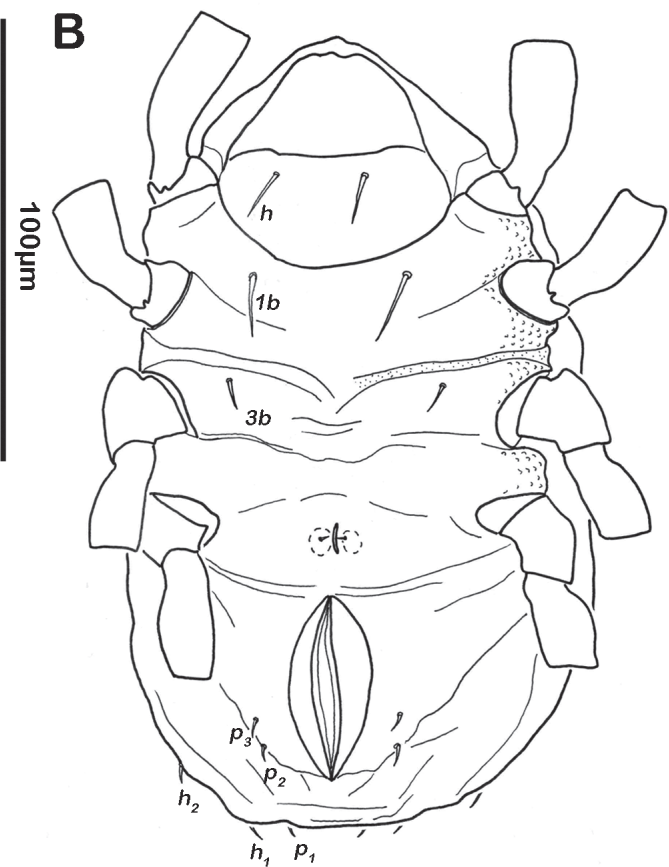

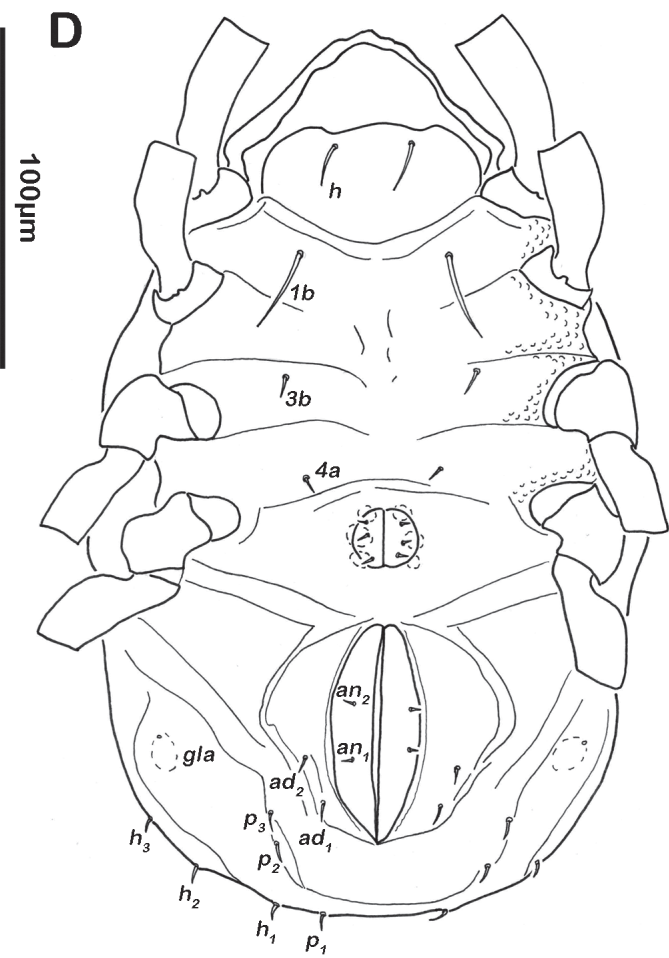

Figure 4. $S$. quasimodo sp. n. nymphs. A protonymph dorsal view $\mathbf{B}$ protonymph ventral view $\mathbf{C}$ tritonymph dorsal view $\mathbf{D}$ tritonymph ventral view. 


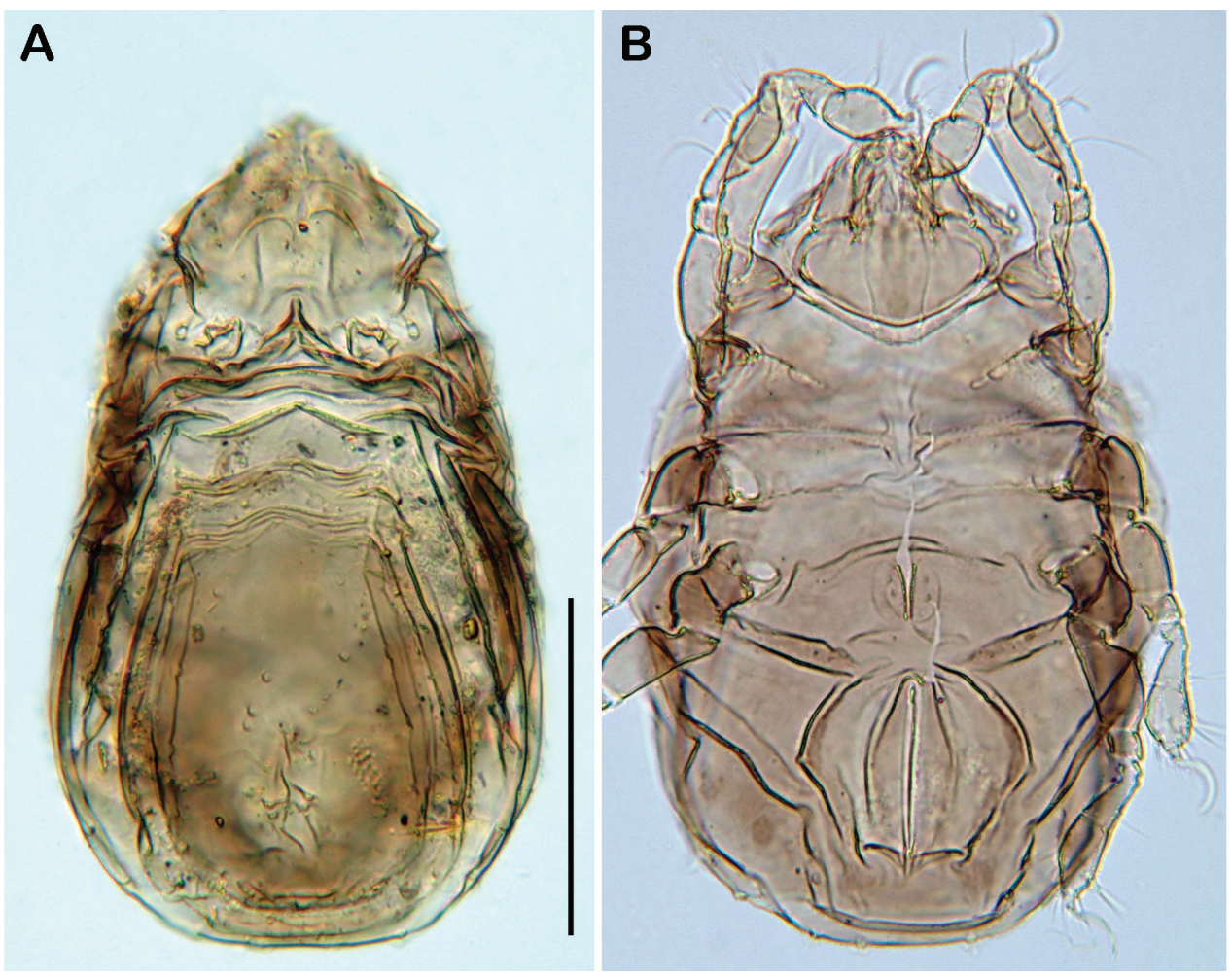

Figure 5. S. quasimodo sp. n. tritonymph, micrographs layered from 5-10 sequentially focused images. A dorsal view $\mathbf{B}$ ventral view. Scale bar $=100 \mu \mathrm{m}$.

Legs. Chaetome and Solenidia see Table 1.

Tritonymph. Length (N=9): 228-266 $\mu$ m (mean $243 \mu \mathrm{m}$ )

Gastronotic region (Fig. 4C, 5A). 44 pairs of notogastral setae, setae of series $c, d$, $l$ and $h$-series further multiplied.

Ventral region of idiosoma (Fig. 4D, 5B). Epimeral setation 1-0-1-1. Three pairs of short genital setae in a longitudinal row. Two pairs of adanal setae $a d_{1-2}$. Two pairs of anal setae $a n_{1-2}$.

Legs (Fig. 6). Chaetome and Solenidia see Table 1.

\section{Selenoribates satanicus sp. $\mathbf{n}$.}

urn:lsid:zoobank.org:act:30EC290D-FD6A-4E7B-B581-30F627ADC954

http://species-id.net/wiki/Selenoribates_satanicus

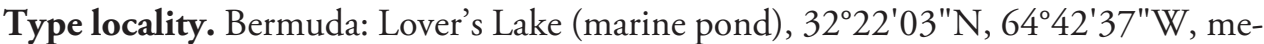
dian eulittoral zone, green algae growing on sandy substrate among mangrove roots, 26 January 2012. 

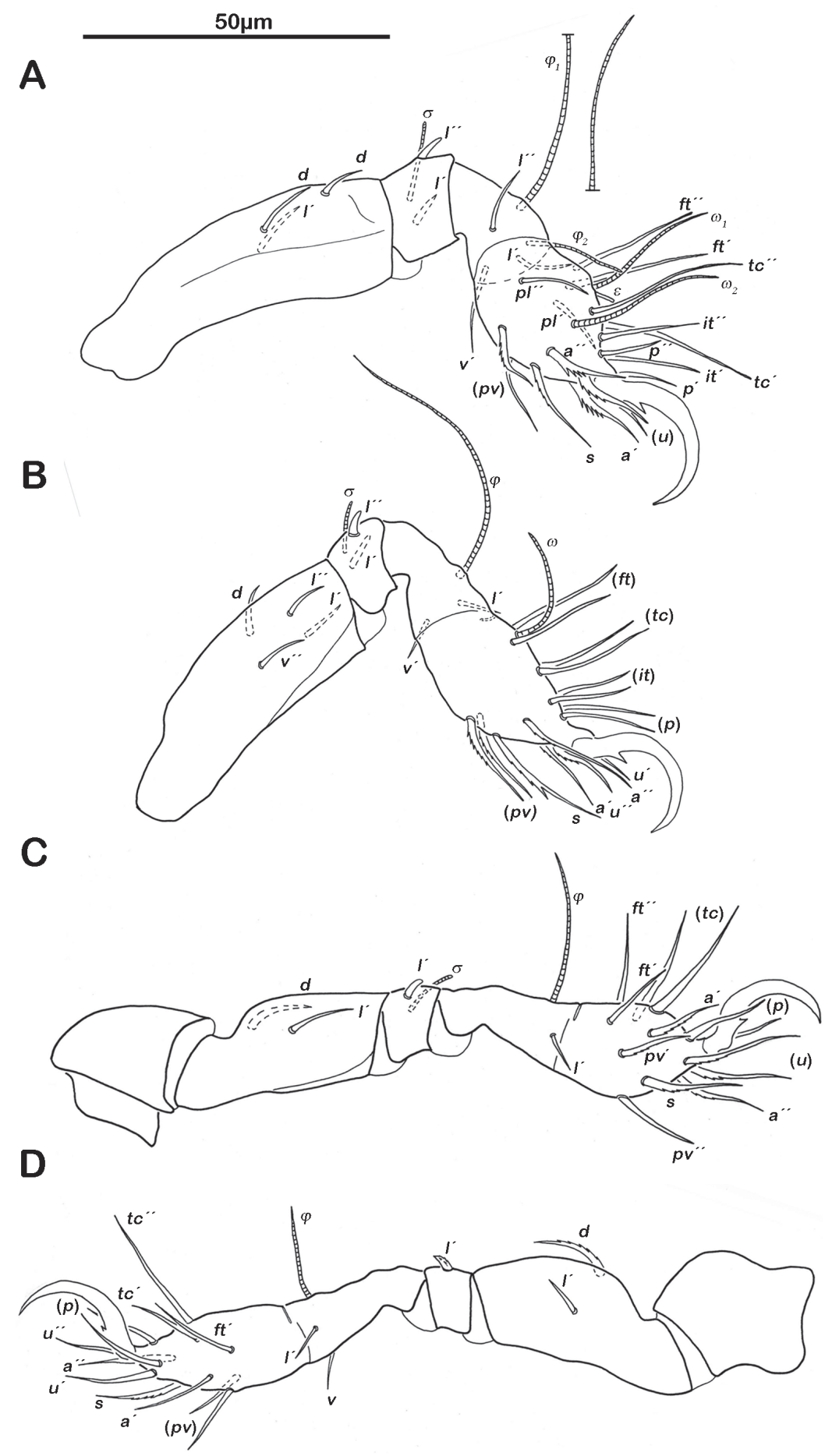

Figure 6. S. quasimodo sp. n. tritonymph legs. A right leg I antiaxial view B right leg II antiaxial view C left leg III antiaxial view D right leg IV antiaxial view. 
A

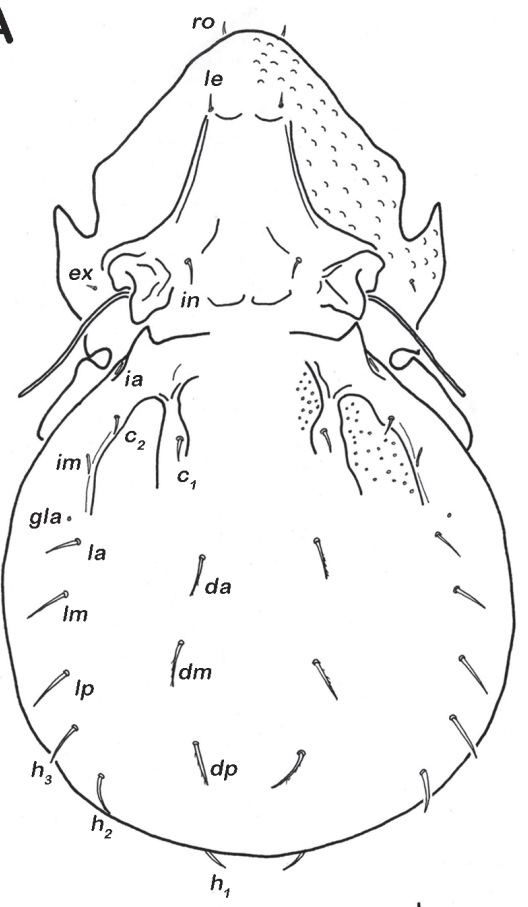

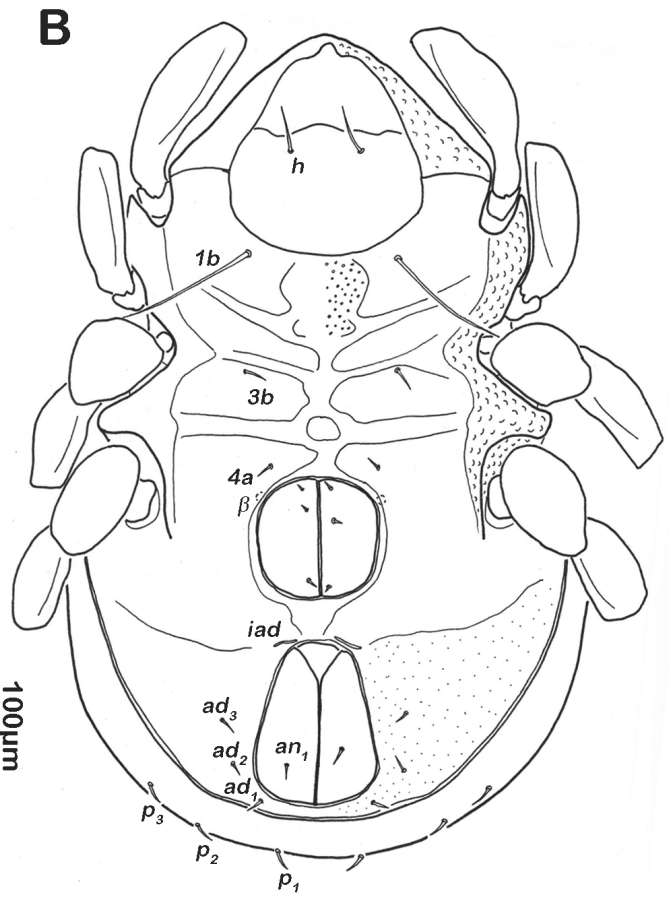

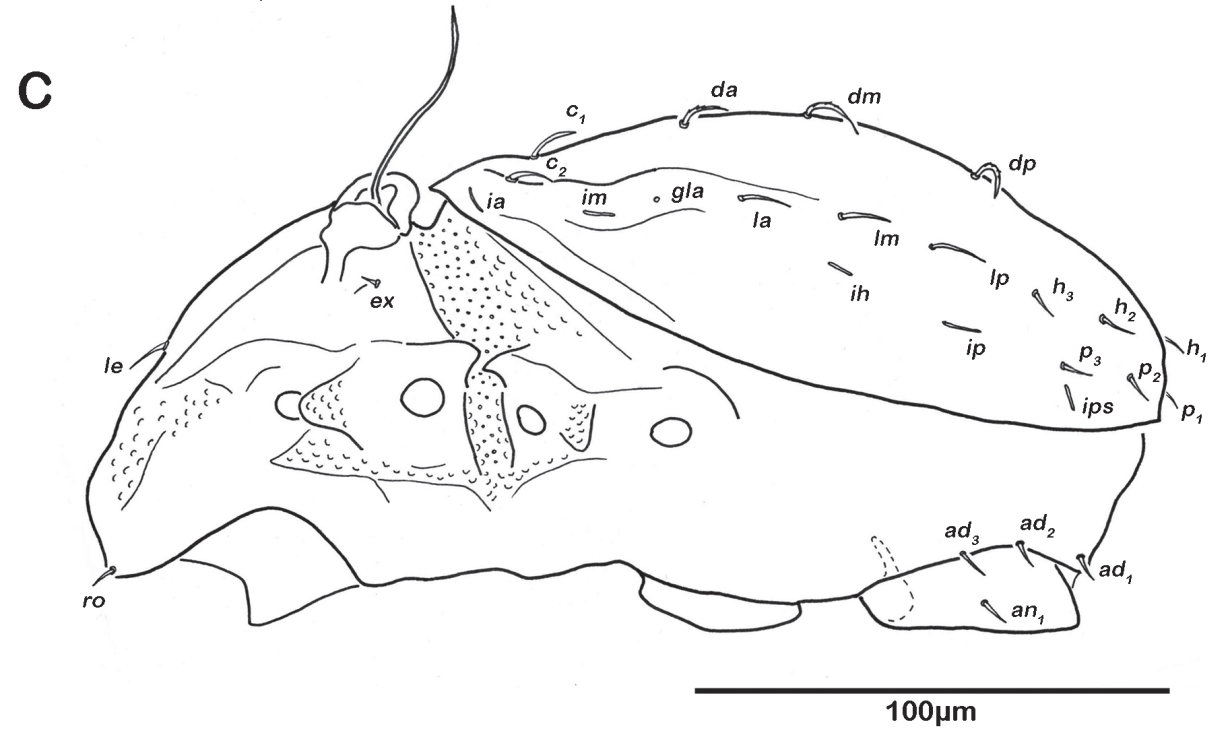

Figure 7. Selenoribates satanicus sp. n. adult. A dorsal view B ventral view $\mathbf{C}$ lateral view.

Type specimen. Holotype: female, preserved in pure ethanol, deposition: Naturhistorisches Museum Wien, collection nr. NHMW 21885. Paratypes: 1 female and 1 male, same locality as holotype; deposition: Senckenberg Museum für Naturkunde Görlitz, collection Nr. 12/48678. 

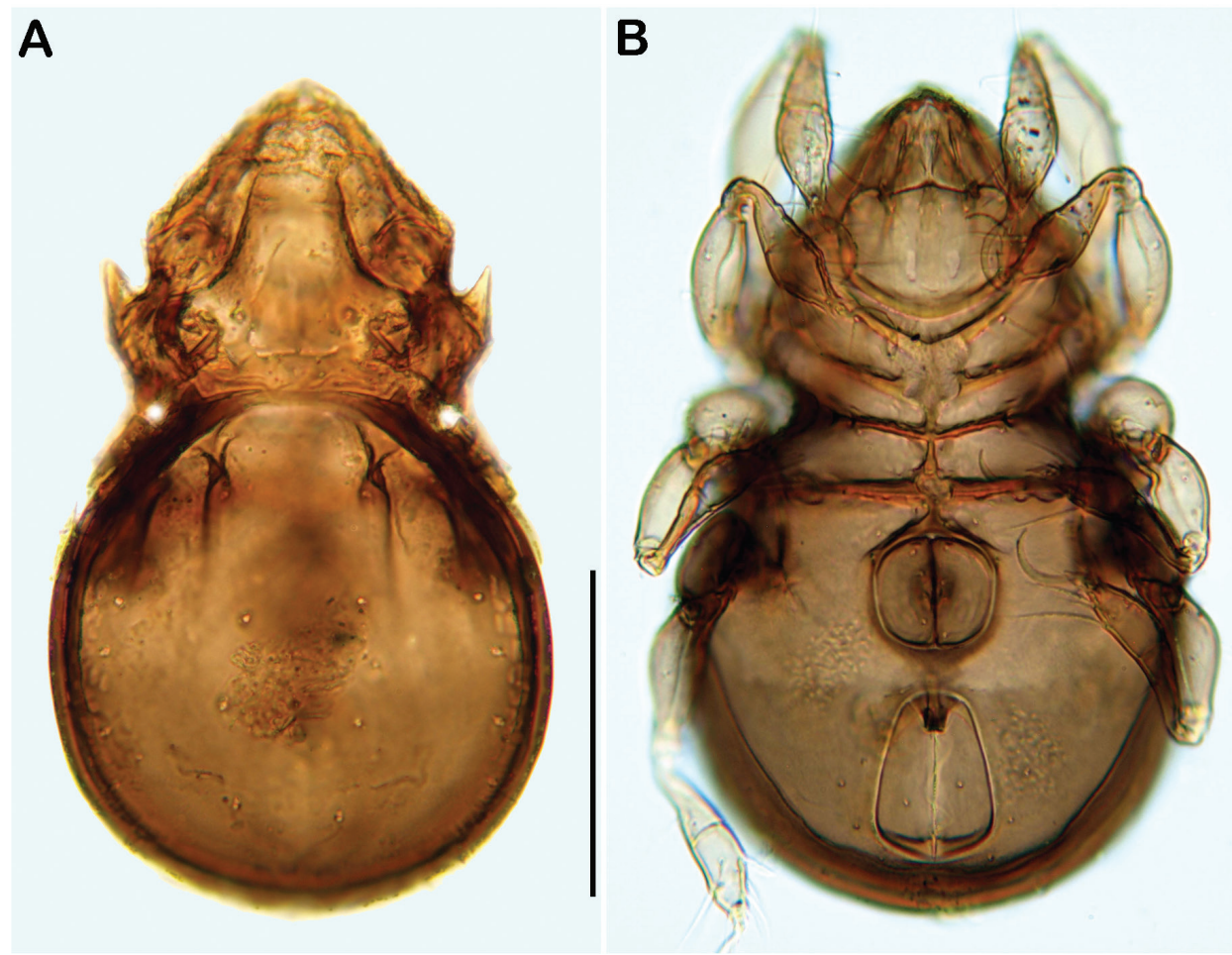

Figure 8. S. satanicus sp. n. adult micrographs layered from 5-10 sequentially focused images. A dorsal view $\mathbf{B}$ ventral view. Scale bar $=100 \mu \mathrm{m}$.

Diagnosis. Light brown sclerotized mites. Average length $283 \mu \mathrm{m}$, mean width $174 \mu \mathrm{m}$. Notogaster rounded in dorsal view, concave in lateral view. Lamellar ridges long reaching lamellar setae. On anterior border of notogaster a pair of horn-like structures. Three notogastral depressions, framed by longitudinal ridges. Fourteen pairs of spiniform notogastral setae. Two median epimeral cavities. Three pairs of genital setae. Three pairs of adanal and one pair of anal setae. Legs monodactylous with large claw. Claw with one proximoventral and one proximodorsal tooth.

Description. Adult: Females ( $\mathrm{N}=6)$, length: $278-308 \mu \mathrm{m}$ (mean $290 \mu \mathrm{m})$, width: 175-188 $\mu \mathrm{m}$ (mean $181 \mu \mathrm{m})$; males (N=5), length: 265-291 $\mu \mathrm{m}$ (mean $274 \mu \mathrm{m}$ ), width: $163-172 \mu \mathrm{m}$ (mean $168 \mu \mathrm{m})$.

Integument. Colour light brown. Cuticle appears granular under dissecting microscope. Cerotegument of prodorsum and notogaster granular. Cerotegument of lateral parts generally finely granular, larger granules in areas surrounding acetabula. Ventral cerotegument generally finely granular, areas laterad of anal opening showing stronger granulation.

Prodorsum. Rostrum rounded in dorsal view, but slightly projecting anteroventrally in lateral view. Rostral setae (ro), lamellar setae (le) and interlamellar setae (in) short and simple. One pair of minute exobothridial setae $(e x)$. Lamellar ridges conspicuous, reaching insertions of lamellar setae. Bothridium large cup with a projecting 


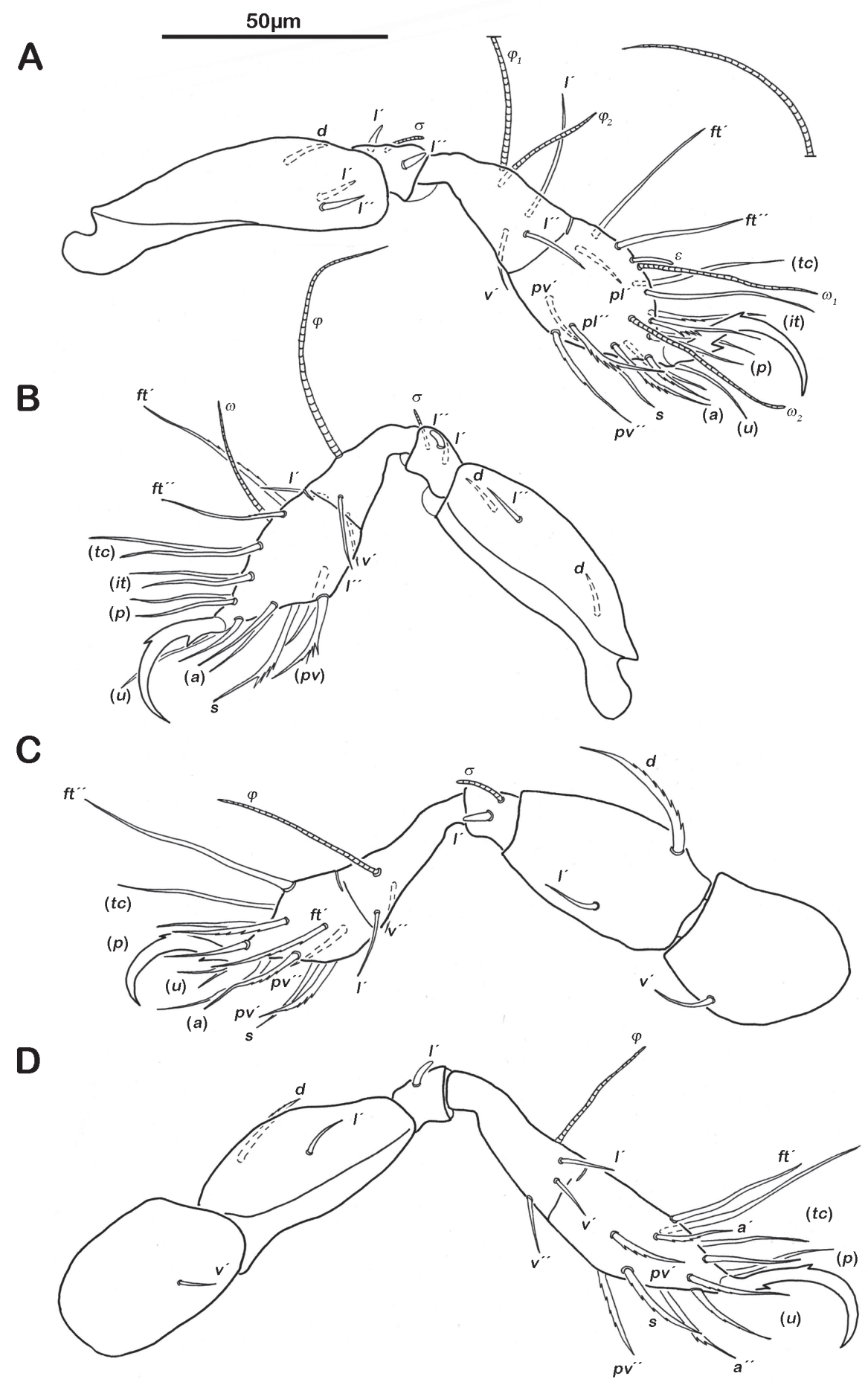

Figure 9. S. satanicus sp. n. legs. A right leg I antiaxial view B right leg II axial view $\mathbf{C}$ right leg III antiaxial view $\mathbf{D}$ left leg IV antiaxial view. 

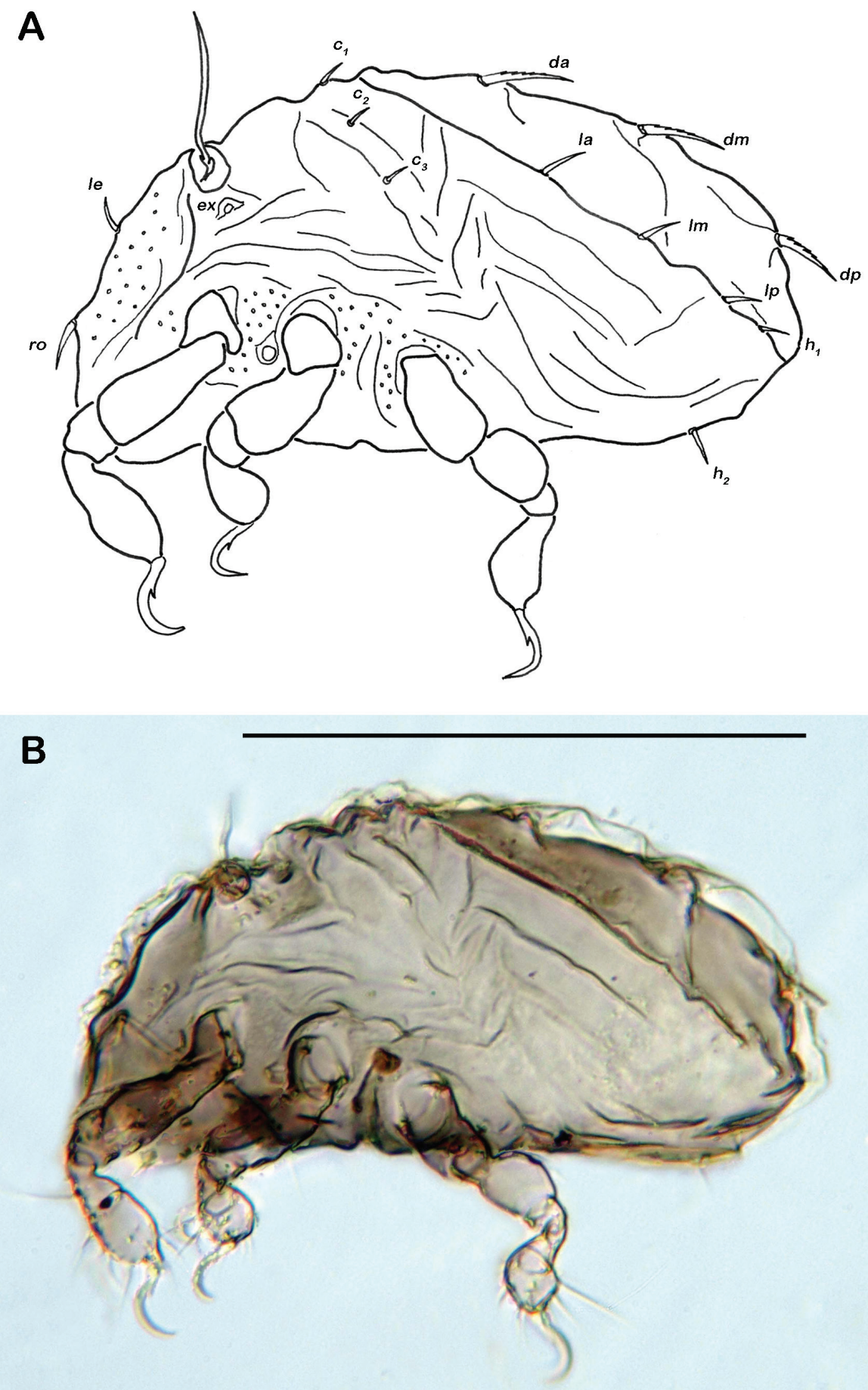

Figure 10. S. satanicus sp. n. larva. A lateral view B lateral view, micrograph layered from 5-10 sequentially focused images. Scale bar $=100 \mu \mathrm{m}$. 
posterior ridge. Sensillus long (ca. $53 \mu \mathrm{m})$ and flagelliform. Tutorium weakly developed and small.

Gnathosoma. Pedipalp pentamerous 0-2-1-3-9 (including solenidion). Solenidion erect, not fused with eupathidium acm. Chelicera chelate, in lateral view forceps-like and each digit with two teeth, whereas from frontal view most distal teeth split into two symmetrical teeth. Distal part of rutellum developed as thin triangular slightly curved inward membrane. Setae $a$ and $m$ long and smooth. Mentum regular, setae $h$ simple, thin and long.

Notogaster (Figs 7A, 8A). Rounded in dorsal view, concave in lateral view. Anterior margin of notogaster incomplete, medially interrupted. On anterior border of notogaster a pair of strongly anteriorly projecting horn-like structures, situated directly posterior of bothridia. Three notogastral depressions on anterior third of notogaster, framed by longitudinal ridges reaching transversal line of setae $l a$ and $d a$. Cerotegument of depressions strongly granular. Fourteen pairs of notogastral setae, $c_{1-2}, d a, d m, d p, l a, l m, l p$, $h_{1-3}, p_{1-3}$ (approximate length $10-13 \mu \mathrm{m}$ ); $c_{3}$ absent. Setae $d a-d p$, slightly serrate, all other setae smooth. Porose areas or distinct pores absent. Five pairs of notogastral lyrifissures present; $i a$ anterior to seta $c_{2}$, in dorsal view hidden under anterior notogastral horn-like projection; im posterior of seta $c_{2}$; lyrifissures $i h$, ip and ips laterally close to lateroventral border of notogastral plate. Orifice of opisthonotal gland $(g l a)$ next to setae $l a$.

Lateral aspect (Figs 7C, 8C). Pedotectum I small but thick, pedotectum II absent. Lateral sejugal furrow broad and deep, showing conspicuous granulation. Enantiophyse consisting of two strong triangular teeth orientated against each other. Anterior tooth slightly rounded. Discidium developed as strong triangular bulge between acetabulum III and IV.

Ventral region of idiosoma (Figs 7B, 8B). Epimeral setation 1-0-1-1, seta $1 b$ long reaching trochanter III, setae $3 b$ and $4 a$ short. Internal borders of all epimera well visible, sternal apodemes II, sejugal and III well developed. A densely granulated median sternal cavity on epimeron I and a second circular median cavity on a level with apodemes III. Three pairs of short and fine genital setae, arranged in longitudinal rows, anterior two pairs of setae close to each other. Insertion of tendon $\beta$ next to anterior corners of genital orifice. Aggenital setae absent. Anal valves triangular. Preanal organ shaped triangular in ventral view. One pair of short anal setae, $a n_{l}$, located on posterior half of anal valves. Three pairs of short and simple adanal setae $a d_{1-3}$. Lyrifissure iad obliquely, adjacent to anterior corners of anal orifice.

Legs (Fig. 9). Monodactylous. Long pointed hook-like claw with one conspicuous proximoventral and a minute proximodorsal tooth. Trochanters III and IV with a triangular dorsodistal projection. Femora exhibiting slightly projecting ventral carinae. All tarsi with one proximal lyrifissure. No porose areas on femora discernable. Solenidion $\varphi_{1}$ on tibia I long, orientated backwards. Chaetome and Solenidia see Table 1.

Larva. Length $(\mathrm{N}=1): 137 \mu \mathrm{m}$

Gastronotic region (Fig. 10). 11 pairs of notogastral setae; setae $c_{1-3}, d a, d m, d p$, la, $l m, l p$ and $h_{1-2}, h_{3}$ absent. Centrodorsal setae $d a, d m$ and $d p$ robust and dorsally serrate, all other setae simple and small.

Ventral region of idiosoma. Epimeral setation 1-0-1. Claparède organ bladderlike. No protecting seta detectable. 
Etymology. When the author regarded S. satanicus in dorsal view for the first time, the oval contour of the notogaster with its two anterior horn-like projections reminded him of the silhouette of the devil's face, therefore the specific name refers to the Hebraic name Satan and is given as adjective in the nominative singular.

\section{Selenoribates elegans sp. $\mathbf{n}$.}

urn:Isid:zoobank.org:act:F9258443-DBA2-408F-890D-2DC72CA9938D

http://species-id.net/wiki/Selenoribates_elegans

Type locality. Bermuda, Whalebone Bay, $32^{\circ} 21^{\prime} 55^{\prime \prime} \mathrm{N}, 64^{\circ} 42^{\prime} 49^{\prime \prime} \mathrm{W}$, lower intertidal area, red algae on rocks, 22 November 2011.

Type specimen. Holotype: female, preserved in pure ethanol, deposition: Naturhistorisches Museum Wien, collection nr. NHMW 21886.

Diagnosis. Red-brown sclerotized mites. Average length $202 \mu$ m, mean width 115 $\mu \mathrm{m}$. Notogaster oval in dorsal view, slightly concave in lateral view. Lamellar ridges absent. Interlamellar setae normal and minute. Two X-shaped ridges on anterior part of notogaster. Fourteen pairs of simple long notogastral setae. Two median epimeral cavities. Claw with two proximoventral and one proximodorsal tooth.

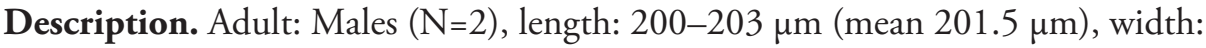
108-122 $\mu \mathrm{m}$ (mean $115 \mu \mathrm{m}$ ).

Integument. Colour light brown. Cuticle showing dotted pattern. Cerotegument of notogaster granular, larger granules in centre of gastronotic plate. Cerotegument of lateral parts granular, with larger granulation in areas surrounding acetabula. Ventral region finely granular, denser granulation laterad of anal orifice.

Prodorsum. Cerotegument strongly granular. Rostrum rounded in dorsal view, but slightly projecting anteroventrally in lateral view. Rostral (ro) and lamellar setae (le) simple and short, interlamellar setae (in) very short. One pair of minute exobothridial setae $(e x)$. Lamellar ridges absent. Bothridium large cup without posterior ridge. Sensillus long (ca. $48 \mu \mathrm{m}$ ), flagelliform.

Gnathosoma. Pedipalp pentamerous 0-2-1-3-9 (solenidion included). Solenidion erect, not fused with eupathidium acm. Chelicera chelate, forceps-like in lateral view, each digit with two teeth, whereas from frontal view most distal teeth split into two symmetrical teeth. Distal part of rutellum a thin triangular slightly inward curved membrane. Setae $a$ and $m$ long and smooth. Mentum regular, setae $h$ simple, thin and long.

Notogaster (Figs 11A, 12A). Rounded in dorsal view, slightly concave in lateral view. Anterior margin of notogaster complete. On anterior part of notogaster a pair of small X-shaped ridges, close to seta $c_{1}$. Fourteen pairs of simple notogastral setae, $c_{1-2}, d a, d m, d p, l a, l m, l p, h_{1-3}, p_{1-3}$ (approximate length 17-20 $\mu \mathrm{m}$ ), setae $c_{3}$ absent. Porose areas or distinct pores absent. Five pairs of notogastral lyrifissures present; ia anterior to seta $c_{2}$; im posterior and laterad of seta $l a$; lyrifissures $i h$, ip and ips laterally close to lateroventral border of notogastral plate. Orifice of opisthonotal gland ( $g l a)$ posterior to seta $c_{2}$. 

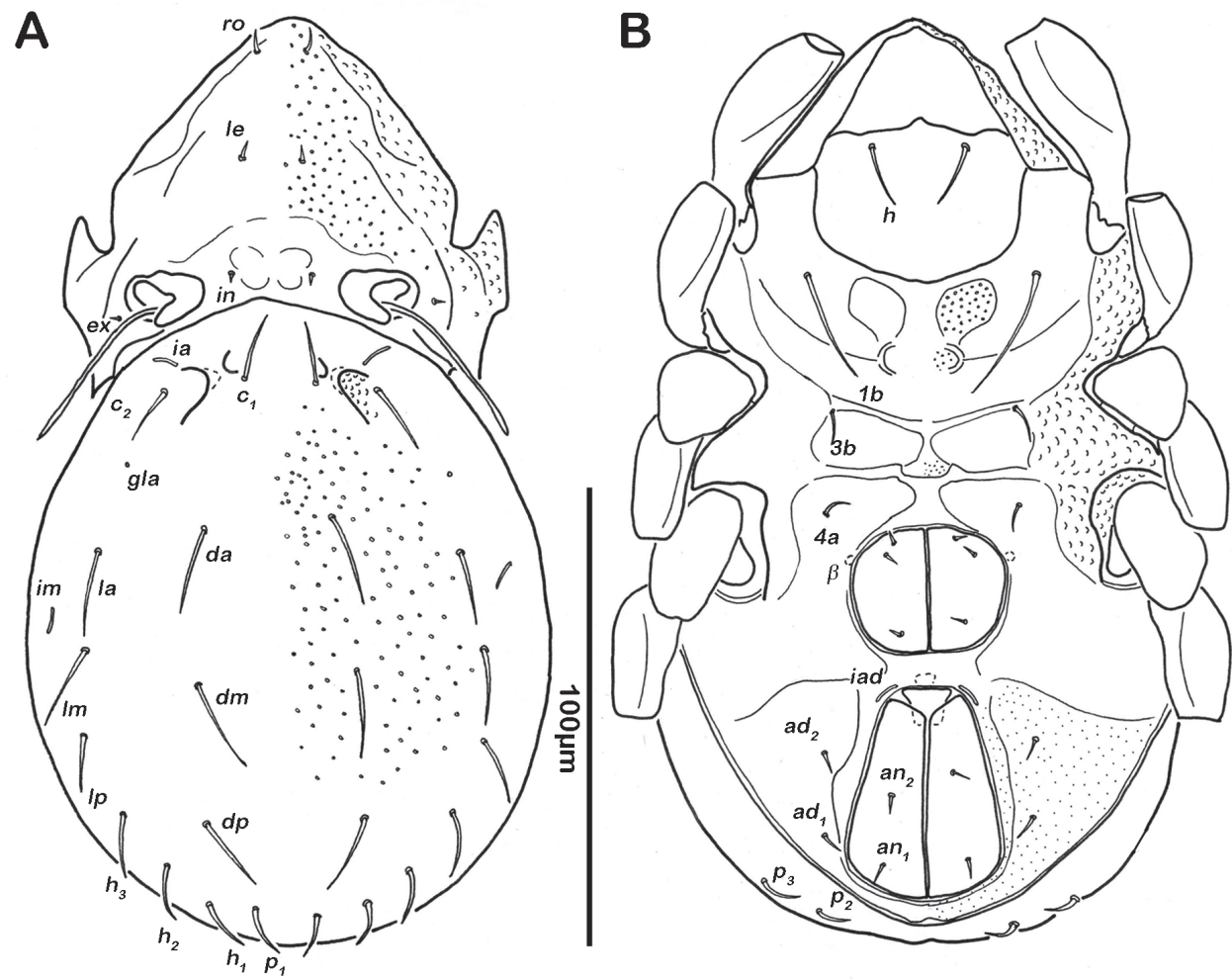

\section{C}

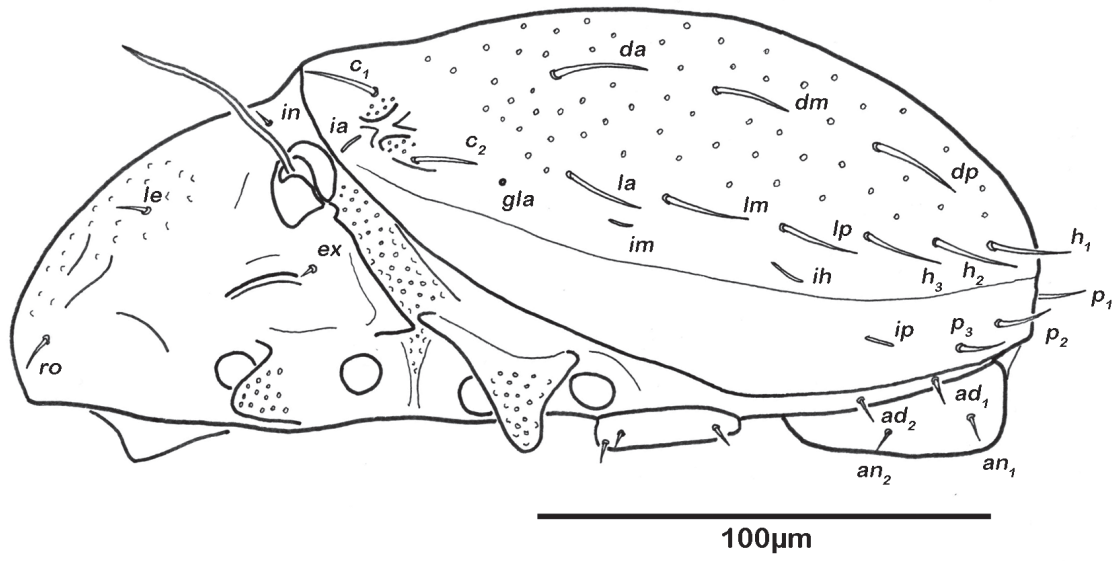

Figure II. Selenoribates elegans sp. n. adult. A dorsal view B ventral view $\mathbf{C}$ lateral view.

Lateral aspect. Pedotectum I small but robust, pedotectum II absent. Enantiophyse consisting of two strong triangular and pointed teeth orientated against each other. Discidium developed as strong triangular projection between acetabulum III and IV. 

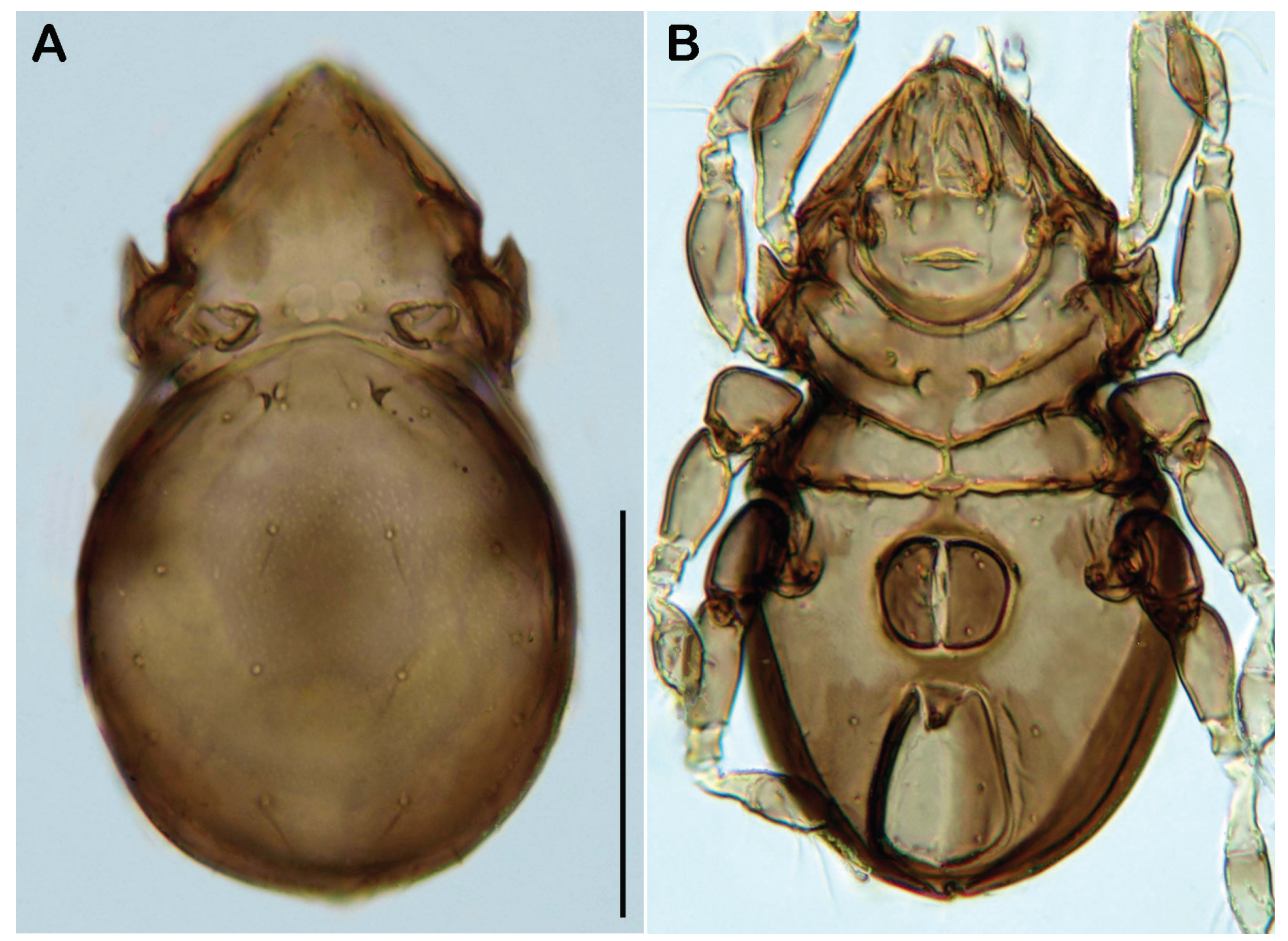

Figure 12. S. elegans sp. n. adult micrographs layered from 5-10 sequentially focused images. A dorsal view B ventral view. Scale bar $=100 \mu \mathrm{m}$.

Ventral region of idiosoma (Figs 11B, 12B). Epimeral setation 1-0-1-1, seta $1 b$ long reaching trochanter III, setae $3 b$ and $4 a$ of normal length and simple. Internal borders of all epimera well visible, sternal apodemes III and IV well developed. Median sternal cavity on epimeron I divided into two anterior symmetric parts and one unpaired posterior part, all parts strongly granulated. A second triangular median cavity on epimeron III on a level with apodeme 3 . Three pairs of short and fine genital setae, arranged in longitudinal rows, anterior pairs close to each other. Insertion of tendon $\beta$ adjacent to anterior corners of genital orifice. Aggenital setae absent. Anal plates triangular. Preanal organ triangular. Two pairs of short anal setae, $a n_{1-2}$. Two pairs of short and simple adanal setae $a d_{1-2}, a d_{3}$ absent. Lyrifissure iad obliquely, next to anterior corners of anal valves.

Legs. Monodactylous. Long acute hook-like claw with two obvious proximoventral teeth, one close to the base of claw and one proximodorsal tooth. Cuticle finely granular. Femora with projecting ventral carinae. All tarsi with one proximal lyrifissure. Porose areas absent. Solenidia $\varphi_{1}$ on tibia I long, orientated backwards. Chaetome and solenidia see Table 1 .

Etymology. The specific name is derived from the Latin word elegans meaning elegant and refers to the slender and delicate shape of the whole body. The name is given as adjective in the nominative singular. 


\section{Key to the Selenoribates species}

1 Three depressions on anterior part of notogaster separated by two X-shaped

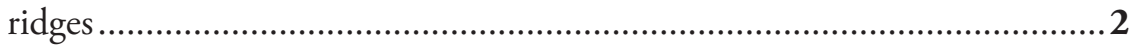

- $\quad$ Depressions and ridges shaped different..................................................... 5

2 Three pairs of anal, four pairs of genital setae

S. ghardaqensis Abd-El-Hamid, 1973

Two pairs of anal setae and three pairs of genital setae

Sensillus fagelliform....

S. mediterraneus Grandjean, 1966

Sensillus flagelliform

.4

Anterior median epimeral cavity simple and shaped circular; lamellar ridges short but conspicuous

S. foveiventris Strenzke, 1961

- $\quad$ Anterior median epimeral cavity divided into two anterior symmetric parts and one unpaired posterior part; lamellar ridges absent........S. elegans sp. $\mathbf{n}$. Three depressions on anterior part of notogaster separated by longitudinal ridges reaching transversal line of setae $l a$ and $d a$; on anterior border of notogaster a pair of horn-like projections .....

S. satanicus sp. $\mathbf{n}$.

- A single large depression on anterior part of notogaster, causing a hunchbacked appearance in lateral view.

S. quasimodo sp. n.

\section{Discussion}

Grandjean (1966) mentioned three depressions separated by two X-shaped ridges on the anterior part of the gastronotic region as diagnostic character of the genus Selenoribates. The new species possess anterior notogastral depressions and sometimes ridges, but they differ in shape and size (Fig. 13). Especially S. quasimodo sp. n. diverges in this respect, showing a single large deepening without any ridges. Notogastral depressions may represent a synapomorphic character of this genus, but the detailed configuration has evolved in different ways. Moreover, Pfingstl and Schuster (2012) described Carinozetes trifoveatus, another selenoribatid species, also exhibiting three anterior gastronotic depressions and two X-shaped ridges, similar to that shown in most of the Selenoribates species. As C. trifoveatus is subject to the same selective constraints of the littoral environment, this character may have evolved convergently. However, median epimeral cavities are also present in Carinozetes Pfingstl \& Schuster, 2012 and in Thalassozetes riparius Schuster, 1963, but the possession of two cavities is unique to the genus Selenoribates. Accordingly, this character state represents another synapomorphy of this taxon, whereas the specific shape of the cavities varies among species (Fig. 14), and hence represents a valuable trait for species discrimination. Comparing the new species with the already known members of Selenoribates, one interesting fact becomes obvious (Table 2). Selenoribates elegans sp. n. shows conformity in most of its morphological features with $S$. foveiventris, S. mediterraneus and S. ghardaqensis, whereas S. quasimodo sp. n. and S. satanicus sp. n. deviate conspicuously from the others as well as from each other. Although S. elegans sp. 

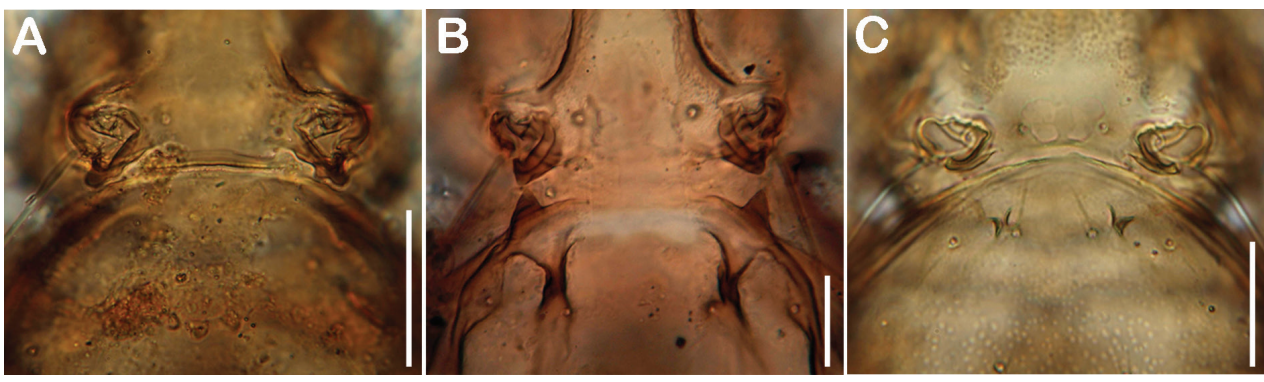

Figure 13. Comparison of cuticular structures on anterior part of gastronotic region. A S. quasimodo sp. n. B $S$. satanicus sp. n. C $S$. elegans sp. n. Scale bars $=30 \mu \mathrm{m}$.
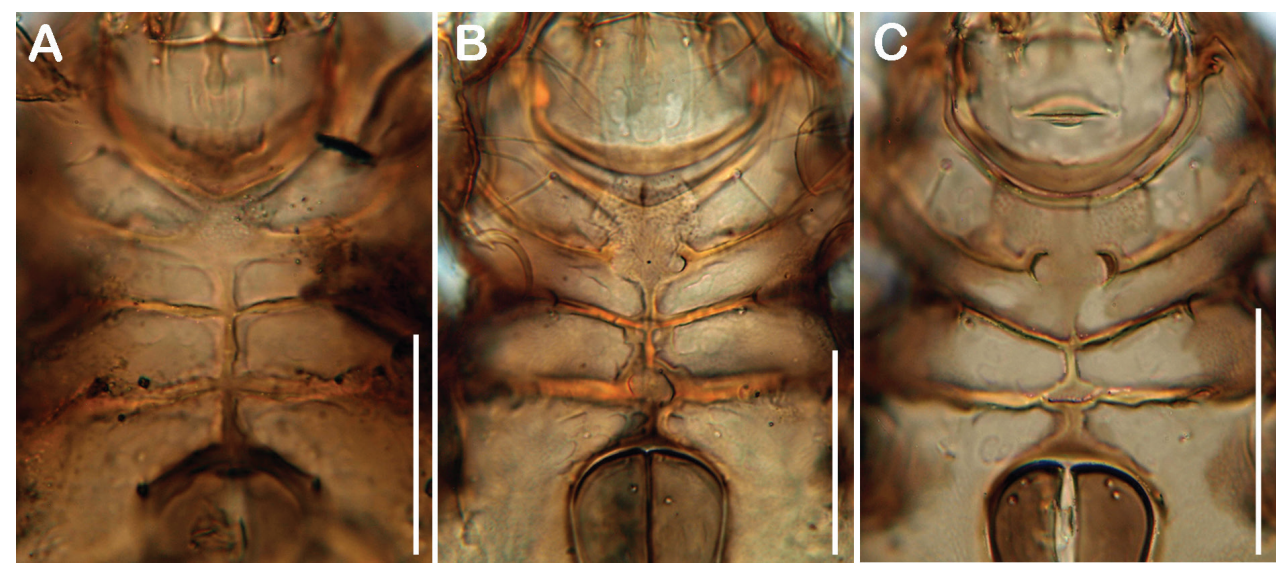

Figure I4. Comparison of ventral cavities. A $S$. quasimodo sp. n. B S. satanicus sp. n. C S. elegans sp. n. Scale bars $50 \mu \mathrm{m}$.

Table 2. Comparison of diagnostic morphological features of all Selenoribates species. ? = no information available; depr. $=$ depression; $\mathrm{X}=\mathrm{X}$-shaped ridge.

\begin{tabular}{c|c|c|c|c|c|c}
\hline & S. foveiventris & S. mediterraneus & S. ghardaqensis & S. quasimodo & S. satanicus & S. elegans \\
\hline size $(\mu \mathrm{m})$ & $240-250$ & $242-251$ & $198-218$ & $212-244$ & $265-308$ & $200-203$ \\
\hline exobothridial seta & vestigial & minute & $?$ & minute & minute & minute \\
\hline lamellar ridges & short & short & short & short & long & absent \\
\hline gastronotic structures & 3 depr. $2 \mathrm{X}$ & 3 depr. $2 \mathrm{X}$ & 3 depr. $2 \mathrm{X}$ & 1 depr. & 3 depr. & 3 depr. $2 \mathrm{X}$ \\
\hline notogastral setae & 14 & 14 & 14 & 14 & 14 & 14 \\
\hline epimeral setae & $1-0-1-1$ & $1-0-1-1$ & $1-0-1-1$ & $1-0-1-1$ & $1-0-1-1$ & $1-0-1-1$ \\
\hline genital setae & 3 & 3 & 4 & 3 & 3 & 3 \\
\hline anal setae & 2 & 2 & 3 & 2 & 1 & 2 \\
\hline adanal setae & 2 & 2 & 2 & 2 & 3 & 2 \\
\hline claw / ventral teeth & 2 & 2 & 2 & 1 & 1 & 2 \\
\hline
\end{tabular}

n. was found on Bermuda, together with the latter species, its morphology suggests that it is closer related to the species from the Mediterranean and the Red Sea. Selenoribates quasimodo sp. n. and S. satanicus sp. n. with their more complex morphological features, 


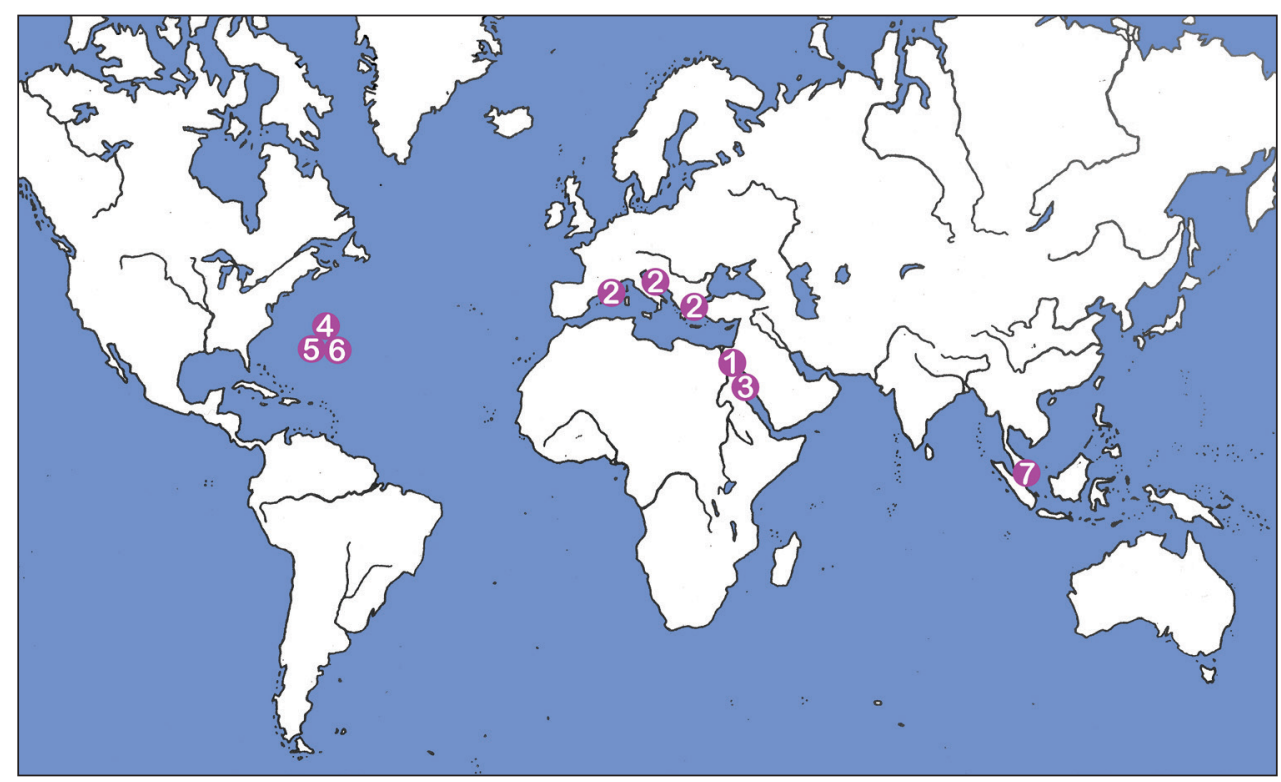

Figure I5. Map showing world distribution of the genus Selenoribates: I S. foveiventris, Egypt (Strenzke 1961) 2 S. mediterraneus, France, Croatia, Greece (Grandjean 1966) 3 S. ghardaqensis, Egypt (Abd-ElHamid 1973) 4 S. quasimodo sp. n., Bermuda 5 S. satanicus sp. n., Bermuda 6 S. elegans sp. n., Bermuda 7 Selenoribates sp., Singapore (leg. Ilse Bartsch).

on the other hand, may represent members of another lineage within the genus Selenoribates. However, the new species are unambiguous members of Selenoribates and based on their morphology, the genus diagnosis provided by Grandjean (1966) should be slightly adjusted as it was done here in the results part.

Knowledge about juvenile morphology of this taxon is largely incomplete and only Grandjean (1966) gave a detailed description of the deuto- and tritonymph of S. mediterraneus. Unfortunately, only the proto- and tritonymph of $S$. quasimodo sp. $\mathrm{n}$. and the larva of S. satanicus sp. n. were available for the present study, so a comprehensive comparison and analysis of the ontogeny is not feasible. Nevertheless, the instars of S. quasimodo sp. n. and S. satanicus sp. n. posses a centrodorsal plate framed by lateral and ventral folds, the typical habitus of selenoribatid juveniles, and further exhibit conformity in most aspects with the nymphs of $S$. mediterraneus, confirming the familial and generic relationship of the species. Besides that, the nymphs of $S$. quasimodo sp. n. show an interesting case of ontogenetic neotrichy with most of the gastronotic setae being duplicated with each moult so that their number increases from stage to stage. This type of neotrichy should be classified as a cosmiotrichy, as the placement of secondary setae follows a distinct arrangement (van der Hammen 1981). Neotrichy shown in juvenile stages is a rare but not unknown phenomenon in oribatid mites. Nymphs of Hydrozetes parisiensis exhibit secondary notogastral setae (Grandjean 1948), the juveniles of Tricheremaeus nemossensis also show neotrichy (Grandjean 1963) and the number of secondary setae is increasing from stage to stage 
in the lohmanniid Annectacarus mucronatus (Grandjean 1950). But in all these examples the neotrichy persists throughout the adult stage, whereas in S. quasimodo sp. $\mathrm{n}$. all the secondary setae get lost in the adults. However, to clarify the nature and the occurrence of this phenomenon in the genus Selenoribates it is necessary to investigate the complete development of all species.

The biogeographic distribution of the genus Selenoribates was formerly limited to the Mediterranean and the Red Sea, but the records of new species from Bermuda clearly demonstrate that members of this genus also exist on coasts of the Western Atlantic. Moreover, littoral samples from Singapore, kindly provided by Ilse Bartsch, also contained specimens of a yet undescribed Selenoribates species. These new findings suggest that members of this genus show a much wider distribution than formerly supposed (Fig. 15) probably occurring on most coasts of tropic and subtropic regions. However, not only the biogeography, but also the diversity of Selenoribates must be reconsidered based on the present data. Bermuda is, with ca. $55 \mathrm{~km}^{2}$, one of the smallest countries of the world and harbours just as much Selenoribates species as the whole Mediterranean and the Red Sea together. Of course the Bermudian intertidal mite fauna may be derived from the Caribbean region and the species found on Bermuda may show a much wider distribution, but this clearly indicates that the real number of species may exceed the presently documented number by far. Pfingstl and Schuster (2012) already stated that within the Caribbean area, with its numerous islands, a relatively high diversity of selenoribatid species should be assumed and the same may apply to many other similar geographic regions, as for example the Indo-pacific area. However, if the genus Selenoribates is much more diverse than formerly known, the question arises why only a few species have been discovered yet and there are several possible answers to this question. First, Selenoribates specimens are relatively small for oribatid mites and may be easily overlooked, second, the littoral environment has been sampled only marginally in matters of oribatid mites and third, it is still unclear which microhabitat within the intertidal zone is usually occupied by Selenoribates species. Even in the present study specimens of this genus were found infrequently and in very small abundances. Accordingly it was not possible to assess if these mites are specifically associated with rocky or sandy substrate or with a specific alga etc. Nevertheless, further studies should answer the question of ecological needs and preferences and maybe then it will be easier to sample Selenoribates and reveal further species.

\section{Acknowledgments}

I am indebted to the Bermuda Institute of Ocean Sciences (BIOS) Inc. and its staff for the provision of research facilities and accommodation. I want to thank Wolfgang Sterrer for his valuable and continuous support. Special thanks to Reinhart Schuster, who discovered the first specimens of Selenoribates quasimodo 40 years ago, for his important advices and help in all respects. Thanks also to Ilse Bartsch providing samples from Singapore; the samples were collected during the Comprehensive Marine Biodi- 
versity Survey of Singapore: International Workshops 2012/2013: Johor Strait Workshop organised by Tan Koh Siang, Peter Ng, Tan Heok Hui and Joelle Lai, National Parks Board and sponsored by Shell Eastern Petroleum (Pte Ltd), Asia Pacific Breweries (Singapore), Care-for-Nature Trust Fund and Hong Kong \& Shanghai Bank. The present research was funded by the Austrian Science Fund (FWF): [J3150].

\section{References}

Abd-El-Hamid ME (1973) Acari (Oribatei) aus Ägypten: Selenoribates ghardaqensis nov. sp. am Roten Meer. Anzeiger der Österreichischen Akademie der Wissenschaften. mathematisch naturwissenschaftliche Klasse 8: 53-55.

Grandjean F (1948) Sur les Hydrozetes (Acariens) de 1'Europe occidentale. Bulletin du Muséum national d'Histoire naturelle 20: 328-335.

Grandjean F (1950) Étude sur les Lohmanniidae (Oribates, Acariens). Archives de Zoologie expérimentale et générale 87: 95-162.

Grandjean F (1963) La néotrichie du genre Tricheremaeus d'après T. nemossensis n. sp. Oribate. Acarologia 5: 284-305.

Grandjean F (1966) Selenoribates mediterraneus n.sp. et les Selenoribatidae (Oribates). Acarologia 8: 129-154.

Grandjean F (1968) Schusteria littorea n.g., n.sp. et les Selenoribatidae (Oribates). Acarologia 10: $116-150$.

van der Hammen L (1981) Numerical changes and evolution in Actinotrichid mites (Chelicerata). Zoologische Verhandelingen 67: 1-78.

Karasawa S, Aoki J (2005) Oribatid Mites (Arachnida:Acari: Oribatida) from the Marine Littoral of the Ryukyu Archipelago, Southwestern Japan. Species Diversity 10: 209-233.

Pfingstl T, Schuster R (2012) Carinozetes nov. gen. (Acari: Oribatida) from Bermuda and remarks on the present status of the family Selenoribatidae. Acarologia 52: 377-409. doi: 10.1051/acarologia/20122067

Pfingstl T (2013) Population dynamics of intertidal oribatid mites (Acari: Cryptostigmata) from the subtropical archipelago of Bermuda. Experimental and Applied Acarology doi: 10.1007/s10493-013-9687-5

Procheş S, Marshall DJ (2001) Global distribution patterns of non-halacarid marine intertidal mites: implications for their origins in marine habitats. Journal of Biogeography 28, 47-58. doi: 10.1046/j.1365-2699.2001.00513.x

Schuster R (1963) Thalassozetes riparius n. gen., n. sp., eine litoralbewohnende Oribatide von bemerkenswerter morphologischer Variabilität (Acari, Oribatei). Zoologischer Anzeiger 171: 391-403.

Schuster R (1989) Transoceanic distribution of air-breathing littoral mites. Progress in Acarology 1: 355-362.

Strenzke K (1961) Selenoribates foveiventris n. gen., n. sp., aus der unterirdischen Feuchtzone der Küste des Roten Meeres (Acarina: Oribatei). Kieler Meeresforschungen 17: 89-93. 


\section{Appendix}

Table of localities. (doi: 10.3897/zookeys.312.5478.app) File format: Microsoft Excel file (xls).

Explanation note: Detailed information on sampling localities of the three new Selenoribates species.

Copyright notice: This dataset is made available under the Open Database License (http://opendatacommons.org/licenses/odbl/1.0/). The Open Database License $(\mathrm{ODbL})$ is a license agreement intended to allow users to freely share, modify, and use this Dataset while maintaining this same freedom for others, provided that the original source and author(s) are credited.

Citation: Pfingstl T (2013) Revealing the diversity of a once small taxon: the genus Selenoribates (Acari, Oribatida, Selenoribatidae). ZooKeys 312: 39-63. doi: 10.3897/zookeys.312.5478 Table of localities. doi: 